\title{
Posterior reversible encephalopathy syndrome induced after blood transfusion for severe anemia
}

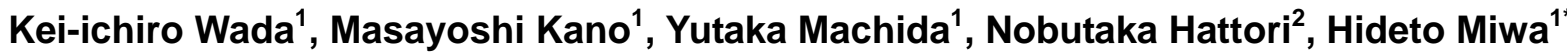 \\ ${ }^{1}$ Department of Neurology, Juntendo University Nerima Hospital, Tokyo, Japan; \\ *Corresponding Author: h.miwa@juntendo-nerima.jp \\ ${ }^{2}$ Department of Neurology, Juntendo University School of Medicine, Tokyo, Japan
}

Received 6 June 2013; revised 30 June 2013; accepted 10 July 2013

Copyright (C) 2013 Kei-ichiro Wada et al. This is an open access article distributed under the Creative Commons Attribution License, which permits unrestricted use, distribution, and reproduction in any medium, provided the original work is properly cited.

\begin{abstract}
Posterior reversible encephalopathy syndrome (PRES) is a clinicoradiological syndrome characterized by headache, confusion, seizures, and cortical visual loss, as well as subcortical edema without infarction on neuroimaging. We report a 56-year-old woman who developed typical manifestations of PRES, 6 days after blood transfusion for severe anemia. Acute volume overloads by transfusion may exceed the capacity of autoregulation of perfusion pressure, possibly resulting in vasogenic edema. We propose that it is clinically important to recognize that rapid correction of anemia by blood transfusion may carry the risk of inducing PRES.
\end{abstract}

Keywords: Posterior Reversible Encephalopathy Syndrome; Anemia; Blood Transfusion

\section{INTRODUCTION}

Posterior reversible encephalopathy syndrome (PRES), or reversible posterior leukoencephalopathy syndrome, is a clinicoradiological syndrome characterized by headache, confusion, seizures, and cortical visual loss, as well as subcortical edema without infarction on neuroimaging [1-3]. It was first described by Hinchey et al. [1] in 1995 based on 15 patients who had subcortical edema without cerebral infarction. To date, a wide variety of clinical conditions have been reported to cause PRES, such as hypertension, exposure to toxic agents, infection, eclampsia, autoimmune disease, and other conditions [1-3]. Recently, we encountered a patient with PRES that was induced after blood transfusion for severe anemia.

\section{CASE REPORT}

A 56-year-old Japanese woman was admitted to the gynecology section in our hospital because of genital bleeding and abdominal pain. Her past medical and family histories were unremarkable, and in particular, she had no past history of hypertension. After admission, she was diagnosed with cancer of the corpus uteri. She had severe anemia with a hemoglobin level of $2 \mathrm{~g} / \mathrm{dL}$, and received blood transfusion with a total of $2 \mathrm{~L}$ packed red blood cells. After transfusion, her hemoglobin level recovered to $9.2 \mathrm{~g} / \mathrm{dL}$ for 4 days. Six days after the last blood transfusion, she suddenly developed status epilepticus, and was referred to our neurological section.

She was immediately treated with general anesthesia by intravenous administration of midazolam with phenytoin. Two days later, she recovered from anesthesia, but a drowsy state continued for a few days. On neurological examination, her pupils were equal, and promptly reactive to light. She could open her eyes if verbal stimuli were given, but she could not recognize any objects. She could not maintain her gaze on any objects, and just stared into space, suggesting that she had cortical blindness. Oculocephalic reflexes, towards either horizontal or vertical directions, were not disturbed. She was mute. No obvious motor paresis was noted in both upper and lower extremities. Deep tendon reflexes were all normal in both limbs. There were no signs of meningeal irritation. Laboratory examination revealed mild anemia $(9.2 \mathrm{~g} / \mathrm{dL})$, leukocytosis $(36,500 / \mu \mathrm{L})$ and elevated C-reactive protein $(4.5 \mathrm{mg} / \mathrm{dL})$. Other routine blood tests, blood coagulation tests, autoantibodies, and neoplastic markers were within normal limits. Cerebrospinal fluid examination revealed a mild increase in protein level $(52 \mathrm{mg} / \mathrm{dL})$. Brain magnetic resonance imaging (MRI), which included T1-, T2and diffusion-weighted images, fluid-attenuated inversion recovery (FLAIR) images, and apparent diffusion coefficient mapping, were performed. The FLAIR images demonstrated high-intensity signal areas in bilateral parietal lobes (Figure 1). Within 10 days, her conscious- 


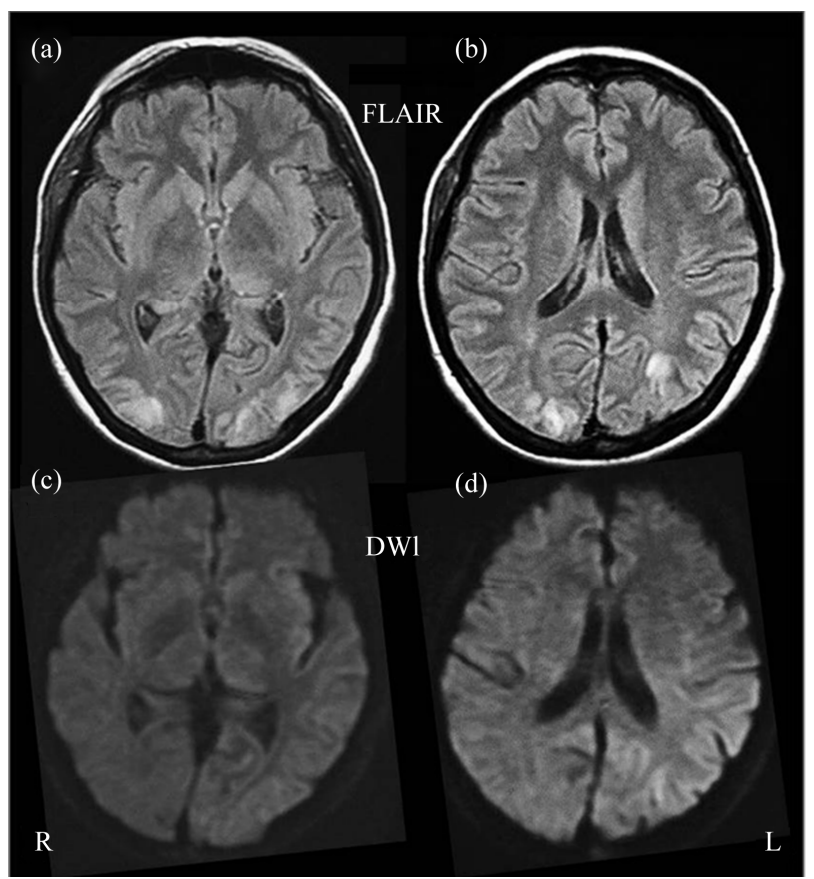

Figure 1. FLAIR imaging (a), (b) and diffusion-weighted MRI (c), (d). FLAIR images demonstrate high-intensity signal areas in bilateral parietal lobes.

ness disturbance fully recovered, as did her visual functions. Abnormal MRI findings also disappeared simultaneously. During the course of illness, her blood pressure generally had been stable within normal ranges $(<130$ $\mathrm{mmHg}$ ) except that acute elevation of blood pressure was transiently noted at the onset of status epileptics, while the maximum systolic/diastolic blood pressure was 180/70 $\mathrm{mmHg}$.

\section{DISCUSSION}

The present patient exhibited conscious impairment, status epilepticus, and cortical blindness. Brain MRI demonstrated white matter lesions in bilateral parietal regions that could be clearly differentiated from ischemic lesions. Both clinical and neuroimaging findings were transient and fully disappeared. Although there are no established consensual criteria for diagnosis of PRES, based on clinical characteristics, we consider that the present patient did have PRES. The pathophysiology of PRES is thought to result from abnormalities in the transmembrane flow of intravascular fluid and proteins caused by two phenomena: one is a cerebral autoregulatory failure, and the other is the loss of integrity of the bloodbrain barrier [2,3]. One important issue is the cause of PRES in the present patient.

Many conditions are known to be potentially associated with PRES [2,3]. No medical treatments were given to her prior to the onset of PRES, except blood transfusion; therefore, it is possible to speculate that blood transfusion and/or rapid correction of severe anemia possibly contributed to inducing PRES in the present case. The literature describes seven adult patients with PRES possibly associated with blood transfusion for anemia (Table 1) [4-9]. It is of particular interest that all the previously reported patients were female. Mean age at onset was $49.8 \pm 13.3$ years $($ mean $\pm \mathrm{SD})$. The mean hemoglobin level before and after blood transfusion was $5.0 \pm 2.9$ and $11.0 \pm 1.7 \mathrm{~g} / \mathrm{dL}$, respectively. The mean time interval between blood transfusion and onset of PRES was $7.3 \pm$ 4.7 days. These clinical data were likely similar to those of the present patient, supporting the speculation that rapid correction of anemia by blood transfusion may potentially induce PRES, particularly in women. We think that such speculation is not unreasonable.

Although the exact pathophysiological mechanisms underlying PRES remain undetermined, it has been suggested that breakdown of cerebral autoregulation respon-

Table 1. Previously reported cases of PRES associated with blood transfusion.

\begin{tabular}{|c|c|c|c|c|c|c|c|}
\hline Patient & Age/sex & $\mathrm{Hb}(\mathrm{g} / \mathrm{dL})(\text { pre/post })^{*}$ & Intervals $^{* *}$ & $\mathrm{HT}^{* * *}$ & Causes of anemia & Sequelae & References \\
\hline 1 & $45 / \mathrm{F}$ & $2.0 / 10.0$ & 2 days & + & Myoma uteri & None & [4] \\
\hline 2 & $48 / \mathrm{F}$ & $3.0 / 8.0$ & 6 days & + & Myuoma uteri & None & [5] \\
\hline \multirow[t]{2}{*}{3} & $47 / \mathrm{F}$ & $1.5 / 10.9$ & 7 days & - & Aplastic anemia & Visual defect & [6] \\
\hline & & & & & & Numbness of extremity & \\
\hline 4 & $58 / \mathrm{F}$ & $7.7 / 10.9$ & 8 days & + & Cancer surgery & None & [7] \\
\hline 5 & $77 / \mathrm{F}$ & $9.2 / 13.3$ & 17 days & + & Cancer surgery & None & [7] \\
\hline 6 & $32 / \mathrm{F}$ & $5.7 / 12.5$ & 5 days & - & Myoma uteri & None & {$[8]$} \\
\hline \multirow[t]{2}{*}{7} & $42 / \mathrm{F}$ & $5.7 / 11.7$ & 6 days & - & Chronic renal failure & None & [9] \\
\hline & & & & & Alcoholic liver cirrhosis & & \\
\hline
\end{tabular}

*Hemoglobin $(\mathrm{Hb})$ levels before and after blood transfusion; ${ }^{* *}$ Intervals between blood transfusion and onset of PRES. 
sible for an increase in cerebral blood flow may play a pivotal role $[2,3]$. Blood transfusion may result in a rapid increase in total blood volume, leading to rapid overload of cerebral blood flow. Cerebral hyperperfusion, if it is acutely induced and exceeds the capacity for autoregulation of perfusion pressure in cerebral capillaries, could result in the huge vasogenic edema responsible for PRES. In addition, the possibility should not be excluded that severe anemia per se also might be the predisposing factor contributing to the induction of PRES, because insufficient oxygen supply due to severe anemia might exert an unfavorable influence on endothelial cell functions, possibly causing a breakdown of the integrity of the bloodbrain barrier in capillary circulation.

Another issue is whether a rapid increase in blood pressure, which is frequently associated with PRES [1-3, 10], simultaneously contributed to inducing PRES in the present study. In this regard, we think that hypertension might not have played a prominent role in the mechanism underlying PRES in the present case. During the course of illness, hypertension was only transiently observed, and an extreme increase in blood pressure $(>180$ $\mathrm{mmHg}$ ) was not noted. Second, three of the seven previously reported patients (Table 1) had no hypertension, suggesting that an acute increase in blood volume, but not acute hypertension, may play a predominant role in inducing PRES, if it occurs after blood transfusion for correction of anemia.

Finally, we propose that it is clinically important to recognize that rapid correction of anemia by blood transfusion may carry a risk of inducing PRES.

\section{REFERENCES}

[1] Hinchey, J., et al. (1996) A reversible posterior leukoencephalopathy syndrome. The New England Journal of Medicine, 2, 494-500.

doi:10.1056/NEJM199602223340803
[2] Legriel, S., Pico, F. and Azoulay, E. (2011) Understanding posterior reversible encephalopathy syndrome. In: Vincent, J.L., Ed., Annual Update in Intensive Care and Emergency Medicine, Springer, Berlin, 631-653.

[3] Feske, S.K. (2011) Posterior reversible encephalopathy syndrome: A review. Seminars in Neurology, 31, 202-215. doi:10.1055/s-0031-1277990

[4] Ito, Y., et al. (1997) Post-transfusion reversible posterior leukoencephalopathy syndrome with cerebral vasoconstriction. Neurology, 49, 1174-1175. doi:10.1212/WNL.49.4.1174

[5] Boughammoura, A., Touzé, E., Oppenheim, C., Trystram, D. and Mas, J.L. (2003) Reversible angiopathy and encephalopathy after blood transfusion. Journal of Neurology, 250, 116-118. doi:10.1007/s00415-003-0940-4

[6] Heo, K., Park, S., Lee, J.Y., Lee, B.I. and Lee, S.K. (2003) Post-transfusion posterior leukoencephalopathy with cytotoxic and vasogenic edema precipitated by vasospasm. Cerebrovascular Diseases, 15, 230-233. doi:10.1159/000068825

[7] Kawano, H., Suga, T., Terasaki, T., Hashimoto, Y., Baba, K. and Uchino, M. (2004) Posterior encephalopathy syndrome in two patients after cancer surgery with transfusion. Rinsho Shinkeigaku, 44, 427-431.

[8] Huang, Y.C., Tsai, P.L., Yeh, J.H. and Chen, W.H. (2008) Reversible posterior leukoencephalopathy syndrome caused by blood transfusion: A case report. Acta Neurologica Taiwanica, 17, 258-262.

[9] Sato, T., et al. (2011) Reversible posterior leukoencephalopathy syndrome after blood transfusion in a patient with end-stage renal disease. Clinical and Experimental $\mathrm{Ne}$ phrology, 15, 942-947. doi:10.1007/s10157-011-0515-0

[10] Li, Y., Gor, D., Walicki, D., Jenny, D., Jones, D., Barbour, P. and Castaldo, J. (2012) Spectrum and potential pathogenesis of reversible posterior leukoencephalopathy syndrome. Journal of Stroke and Cerebrovascular Diseases, 21, 873-882.

doi:10.1016/j.jstrokecerebrovasdis.2011.05.010 